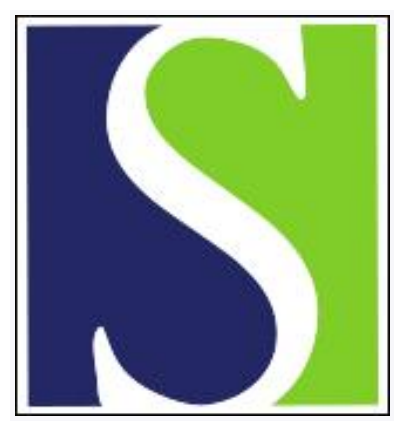

Scand J Work Environ Health 2009;35(6):454-461

https://doi.org/10.5271/sjweh.1352

Published online: 09 Sep 2009, Issue date: 00 Dec 2009

Occupational exposure and incidence of respiratory disorders in a general population

by Skorge TD, Eagan TML, Eide GE, Gulsvik A, Bakke PS

Affiliation: Department of Thoracic Medicine, Haukeland University Hospital, N-5021 Bergen, Norway. trude.skorge@med.uib.no

Key terms: general population; incidence; JEM; Job Exposure Matrix; occupational exposure; respiratory disorder

This article in PubMed: www.ncbi.nlm.nih.gov/pubmed/19806271

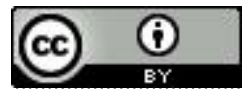




\title{
Occupational exposure and incidence of respiratory disorders in a general population
}

\author{
by Trude D Skorge, MD, ${ }^{1,2}$ Tomas ML Eagan, MD, PhD, ${ }^{2}$ Geir Egil Eide, CandReal, DrPhilos, ${ }^{3,4}$ Amund \\ Gulsvik, MD, PhD, 1, 2 Per S Bakke, MD, PhD ${ }^{1,2}$
}

Skorge TD, Eagan TML, Eide GE, Gulsvik A, Bakke PS. Occupational exposure and incidence of respiratory disorders in a general population. Scand J Work Environ Health. 2009;35(6):454-460.

Objective Our aim was to study the effect of occupational exposure on the incidence of adult asthma and six respiratory symptoms using a job-exposure matrix (JEM).

Methods From 1985, we conducted an 11-year community cohort study on the incidence of asthma and respiratory symptoms in Western Norway ( $\mathrm{N}=2401$, aged $15-70$ years at baseline). The analyses in the current study were based on subjects $\leq 65$ years at baseline, since those $>65$ years were unlikely to experience significant occupational exposures within the follow-up period.

Results More women than men were exposed to biological dust (38\% versus $29 \%$ ), while more men than women were exposed to mineral dust ( $48 \%$ versus $19 \%$ ), and gas or fumes ( $58 \%$ versus $53 \%$ ). After adjusting for age, educational level, smoking, and previous occupational exposures, we found that high exposure to biological dust exposure was significantly related to a higher incidence of chronic and morning cough in men; for women, low exposure was related to attacks of dyspnea. Low exposure to workplace gas or fumes was significantly related to incident phlegm cough and attacks of dyspnea for women, while for men, high exposure was related to dyspnea grade 2. For the incidence of asthma and phlegm cough, after adjusting for all confounders, we found a significant interaction between workplace exposures and gender, where women had a higher risk of disease.

Conclusions Assessed by a JEM, occupational airborne exposure was weakly related to the incidence of asthma and respiratory symptoms, significantly more so for women than for men.

Key terms Job Exposure Matrix; JEM.

Community studies and those on working populations have shown that airborne occupational exposure is related to asthma and respiratory symptoms (1-5). A paper on the Hordaland County Cohort Study showed that approximately $14 \%$ of incident adult asthma is attributable to occupational exposure in a general population (1). The advantage of examining the relationship between occupational exposures and asthma in the population at large, compared to working groups, is that the risk of selection bias is reduced. However, most general population studies have used rather crude measures of self-reported exposure due to the complexity of obtaining detailed work exposure history. The disadvantage is a loss in precision when characterizing exposure. To remedy this, job-exposure matrices (JEM) have been developed, where the job title is translated into exposure to specific agents $(2,6-8)$.

Two studies from the European Community Respiratory Health Survey (ECRHS) used different JEM. The first study used a revised community-based JEM (ie, the so-called "ALOHA JEM"), which distinguished between exposure to biological dust, mineral dust, gas or fumes $(2,9)$. This JEM was elaborated for the follow-up of the ECRHS; the study by Sunyer et al showed that occupational exposure was associated with an increased incidence of chronic bronchitis symptoms (chronic phlegm) (2). The second study utilized an asthma-specific JEM that included 18 different substances characterized as being of high risk $(7,10)$.

1 Institute of Medicine, University of Bergen, Bergen, Norway.

2 Department of Thoracic Medicine, Haukeland University Hospital, Bergen, Norway.

3 Centre for Clinical Research, Haukeland University Hospital, Bergen, Norway.

4 The Epiforsk Research Group, Department of Public Health and Primary Health Care, University of Bergen, Bergen, Norway.

Correspondence to: Dr TD Skorge, Department of Thoracic Medicine, Haukeland University Hospital, N-5021 Bergen, Norway. [E-mail: trude.skorge@med.uib.no] 
The Hordaland County Cohort Study comprised an established population cohort with a wide age span and information about several important confounders, which could potentially expand on the knowledge obtained from the ECRHS.

Previous data from the Hordaland County cohort using self-reported exposure have shown a strong effect of occupational exposure on asthma and respiratory symptoms. The primary aim of our study was to describe the association between occupational exposure, estimated by a JEM, and the incidence of adult asthma and six respiratory symptoms. In addition, we wanted to see if there were differences between genders in the effect of occupational exposure on the incidence of symptoms.

\section{Methods}

\section{Study population}

The baseline survey was conducted in 1985. A random sample $(\mathrm{N}=4995)$ of the population in the city of Bergen and 11 surrounding municipalities in Hordaland County, Western Norway, aged 15-70 years, received a mailed questionnaire concerning respiratory health, smoking habits, and occupational exposure prior to 1985. After two reminder letters, 3370 subjects $(89 \%)$ responded. No difference in smoking-habits or prevalence of respiratory symptoms between responders and non-responders was seen (11). Eleven years after the initial survey, 189 subjects had deceased, leaving 3181 subjects eligible for the follow-up study that was conducted between September 1996 and May 1997. A total of 2819 subjects $(89 \%)$ returned a mailed questionnaire after a maximum of two reminder letters and one telephone call (12).

Of this sample, $2401(76 \%)$ also attended a clinical examination at Haukeland University Hospital $(13,14)$. During this visit, the participants completed a questionnaire that included a detailed job history of the period 1985-1996/97. In our study, we included only subjects from the follow-up aged 15-65 years in 1985 ( $\mathrm{N}=2312$ ), since those $>65$ years were unlikely to experience significant occupational exposures within the follow-up period.

\section{Questionnaires}

The subjects were asked to report the type of job held, the name of their employer, and in what kind of industry they worked, together with year started and year ended in the specific job. This information was requested for all jobs (maximum of ten different jobs) held from 1985-1996/97, and was checked by a technician after completion.

All jobs for each individual were coded according to the Nordic Classification of Occupations system (15). In 2005/06, all jobs were re-coded according to the International Standard Classification of Occupations-88 (ISCO-88) system (International Labour Office 1990).

We used the ALOHA-JEM to classify all the jobs that an individual had held with "no", "low" or "high" exposure to biological dust, mineral dust, and/or gas or fumes based on the ISCO- 88 job codes $(2,4,8)$. Thus, for each exposure type there were three exposure categories during follow up: (i) no job with exposure, (ii) at least one job with low exposure, but no high exposure, and (iii) at least one job with high exposure.

The wording of the questions on asthma and respiratory symptoms was identical in 1985 and 1996/97, except for the question on wheezing. In 1985, the questions were: "Have you ever been treated by a doctor or been hospitalized for asthma? [yes, no]"; "Do you have phlegm when coughing? [yes, no]"; "Do you have a cough for 3 months or more altogether during a year? [yes, no]"; "Do you usually cough or clear your throat in the morning? [yes, no]"; "Are you breathless when you climb two flights of stairs at an ordinary pace? [yes, no]"; "Do you sometimes experience attacks of breathlessness? [yes, no]"; and "Do you ever have wheezing in your chest [yes, no]. In 1996/97, an additional question was added: "Have you had wheezing in your chest in the last 12 months? [yes, no]".

\section{Statistical analyses}

We defined the cumulative incidence of a single symptom or asthma as: (the number of new cases in 1996/97)/ (the number of subjects in 1985 not having the symptom or asthma) (16). We used the Chi-square test or test for trend to compare the prevalence of the different exposures between men and women, and the incidence of respiratory symptoms and asthma for each exposure category, respectively.

Associations between occupational exposures during follow-up and the cumulative incidence of asthma and respiratory symptoms were evaluated using logistic regression analyses. The different exposure types (biological dust, mineral dust, gas or fumes, or any of the three exposures) were considered individually, comparing individuals with no exposure to those with (i) high and (ii) low, but never high exposure.

We adjusted for age, educational level at followup, smoking habits, pack years [(the number of cigarettes smoked per day) / (20) $\times$ (the number of years smoked)] up until follow-up, and self-reported occupational exposure before baseline in all models. We also adjusted for environmental tobacco smoke (ETS) in pregnancy, childhood, and adulthood. ETS did not significantly alter the associations, and was omitted from the final models. 
We estimated the first order interactions between the exposure(s) in question and gender, age, and smoking through separate analyses. All analyses were conducted with Stata 9.0 (StataCorp LP, College Station, TX, USA).

\section{Results}

The characteristics of the study population are given in table 1. Daily smoking decreased during the follow-up time from 1985-1996/97, particularly in men. The prevalence of all respiratory symptoms and asthma increased during these 11 years, more in the case of women than men. For asthma, the prevalence doubled from approximately $3 \%$ to $6 \%$ for both genders.

An overview of occupations held at least once by each gender, is given in table 2 . As expected, there were considerable differences between the genders, with men more likely to have held industry-type jobs, and women more likely to have worked in the health sector. The two most common occupations amongst the group "other manual service" were waitresses and similar restaurant jobs, and child care workers. The restaurant business is known for having a transient workforce, which helps explain the large number of subjects in that category.

The proportion of subjects exposed to the various types and levels of workplace dust, gas, and fumes is given in table 3 . Significantly more women than men were exposed to biological dust (38\% versus $29 \%$ ),

Table 1. Characteristics of the study population aged $\leq 65$ years in the Hordaland County Cohort Study at baseline and follow-up.

\begin{tabular}{|c|c|c|c|c|}
\hline & \multicolumn{2}{|c|}{ Men $(N=1123)$} & \multicolumn{2}{|c|}{ Women $(\mathrm{N}=1189)$} \\
\hline & Baseline & Follow-up & Baseline & Follow-up \\
\hline Mean age & 37.3 & 48.3 & 38.2 & 49.2 \\
\hline \multicolumn{5}{|l|}{ Smoking status (\%) } \\
\hline Current & 42.2 & 35.4 & 37.7 & 32.6 \\
\hline Ex & 23.1 & 31.9 & 16.8 & 23.6 \\
\hline Never & 34.7 & 32.7 & 45.5 & 43.8 \\
\hline \multicolumn{5}{|l|}{ Pack years $(\%)^{a}$} \\
\hline $1-9$ & . & 22.6 & . & 27.7 \\
\hline $10-19$ & . & 21.4 & . & 17.0 \\
\hline$\geq 20$ & . & 23.4 & - & 11.8 \\
\hline \multicolumn{5}{|c|}{ Respiratory symptoms (\%) } \\
\hline Phlegm & 25.2 & 26.6 & 17.5 & 22.1 \\
\hline Chronic cough & 11.0 & 12.3 & 8.2 & 13.1 \\
\hline Morning cough & 23.3 & 24.9 & 18.6 & 26.1 \\
\hline Dyspnea grade 2 & 8.0 & 11.9 & 11.2 & 20.0 \\
\hline Attacks of dyspnea & 11.2 & 13.4 & 13.1 & 16.8 \\
\hline Wheezing & 21.7 & 22.7 & 18.8 & 23.6 \\
\hline Asthma (\%) & 3.6 & 6.1 & 2.6 & 5.7 \\
\hline
\end{tabular}

a Based on reported smoking at follow-up. while significantly more men were exposed to mineral dust (48\% versus $19 \%)$ and gas or fumes (58\% versus $53 \%)$.

The incidence of adult asthma and respiratory symptoms by level of occupational exposure are given in table 4. For women with low exposure to biological dust, the incidence of attacks of dyspnea was significantly higher compared to unexposed women. Among women with high exposure to mineral dust, the incidence of phlegm cough was significantly increased. Women with

Table 2. Occupational categories by gender in subjects $\leq 65$ years at baseline.

\begin{tabular}{|c|c|c|c|c|}
\hline \multirow[t]{2}{*}{ Occupational categories } & \multicolumn{2}{|c|}{ Men } & \multicolumn{2}{|c|}{ Women } \\
\hline & $\mathrm{N}$ & $\%$ & $\mathrm{~N}$ & $\%$ \\
\hline Consistently white-collar & 273 & 17.6 & 244 & 15.0 \\
\hline \multicolumn{5}{|c|}{ At least once in the following sectors } \\
\hline Healthcare & 40 & 2.6 & 220 & 13.5 \\
\hline Cleaning & 37 & 2.4 & 174 & 10.7 \\
\hline Transport & 214 & 13.8 & 29 & 1.8 \\
\hline Other manual service & 107 & 6.9 & 505 & 31.0 \\
\hline Construction & 151 & 9.8 & 2 & 0.1 \\
\hline Painting & 33 & 2.1 & 0 & 0.0 \\
\hline Metal industry & 156 & 10.1 & 11 & 0.7 \\
\hline Chemical and related & 11 & 0.7 & 5 & 0.3 \\
\hline Electrical & 69 & 4.5 & 4 & 0.2 \\
\hline Wood, paper, and textile & 42 & 2.7 & 47 & 2.9 \\
\hline Food processing & 36 & 2.3 & 22 & 1.4 \\
\hline Other industry and mining & 33 & 2.1 & 6 & 0.4 \\
\hline Agriculture, fishery, forestry & 34 & 2.2 & 19 & 1.2 \\
\hline Not classifiable & 311 & 20.1 & 341 & 20.9 \\
\hline
\end{tabular}

Table 3. Descriptive statistics of occupational exposures using a job-exposure matrix (JEM) in subjects $\leq 65$ years at baseline in the Hordaland County Cohort Study.

\begin{tabular}{|c|c|c|}
\hline & Men $(\mathrm{N}=1123)$ & Women $(\mathrm{N}=1189)$ \\
\hline & $(\%)$ & $(\%)$ \\
\hline \multicolumn{3}{|c|}{ Biological dusta } \\
\hline None & 70.9 & 62.4 \\
\hline Low & 21.1 & 34.8 \\
\hline High & 8.0 & 2.8 \\
\hline \multicolumn{3}{|c|}{ Mineral dust ${ }^{a}$} \\
\hline None & 52.4 & 81.0 \\
\hline Low & 30.0 & 16.0 \\
\hline High & 17.6 & 3.0 \\
\hline \multicolumn{3}{|c|}{ Gas or fumes a } \\
\hline None & 41.9 & 47.0 \\
\hline Low & 31.0 & 48.8 \\
\hline High & 27.1 & 4.2 \\
\hline \multicolumn{3}{|c|}{ Any of the above ${ }^{a}$} \\
\hline None & 37.6 & 41.4 \\
\hline Low & 25.1 & 51.6 \\
\hline High & 37.3 & 7.0 \\
\hline
\end{tabular}


high exposure to gas or fumes had a significantly higher incidence of asthma, phlegm, and attacks of dyspnea than those with low or no exposure.

Men with high exposure to biological dust had a higher incidence of chronic cough and morning cough, compared to men with low or no exposure. The incidence of dyspnea grade 2 and wheezing was significantly higher for men with high exposure to gas or fumes than for those with low or no exposure. For all the other respiratory symptoms, the trend was the same but did not reach statistical significance (table 4).

The results from the logistic regression analyses are shown in table 5. In women, high or low exposure to biological or mine dust was associated with a higher risk of asthma and most symptoms. However, this was

Table 4. The 11-years cumulative adult incidence (\%) of asthma and respiratory symptoms by occupational exposure using a jobexposure matrix (JEM) stratified by gender in subjects $\leq 65$ years at baseline.

Asthma Phlegm Chronic Morning Dyspnea Attacks Wheez

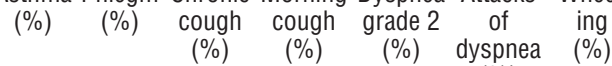

$(\%)$

\begin{tabular}{|c|c|c|c|c|c|c|c|}
\hline \multicolumn{8}{|l|}{ Men } \\
\hline \multicolumn{8}{|c|}{ Biological dust } \\
\hline None & 3.2 & 17.5 & $7.2^{\mathrm{a}}$ & $13.6^{a}$ & 8.6 & 9.2 & 12.8 \\
\hline Low & 4.3 & 22.9 & $10.3^{a}$ & $19.5^{\mathrm{a}}$ & 8.3 & 9.5 & 19.4 \\
\hline High & 7.9 & 18.6 & $16.5^{\mathrm{a}}$ & $28.4^{\mathrm{a}}$ & 8.5 & 13.4 & 16.2 \\
\hline \multicolumn{8}{|c|}{ Mineral dust } \\
\hline None & 4.8 & 20.0 & 7.9 & 16.4 & 7.5 & 8.5 & 12.6 \\
\hline Low & 2.5 & 18.2 & 9.4 & 16.5 & 11.0 & 10.8 & 16.2 \\
\hline High & 3.1 & 15.6 & 9.4 & 13.6 & 7.3 & 11.0 & 17.0 \\
\hline \multicolumn{8}{|c|}{ Gas or fumes } \\
\hline None & 4.0 & 17.8 & 8.0 & 15.0 & $7.5^{\mathrm{a}}$ & 8.6 & $10.9^{a}$ \\
\hline Low & 3.9 & 21.3 & 7.8 & 15.7 & $6.3^{\mathrm{a}}$ & 7.9 & $16.2^{\mathrm{a}}$ \\
\hline High & 3.4 & 17.2 & 10.5 & 17.5 & $12.7^{\mathrm{a}}$ & 13.4 & $18.3^{\mathrm{a}}$ \\
\hline \multicolumn{8}{|c|}{ Any of the above } \\
\hline None & 4.2 & 16.7 & 7.4 & 13.9 & 7.4 & 8.8 & $11.1^{\mathrm{a}}$ \\
\hline Low & 3.0 & 23.9 & 8.8 & 17.1 & 7.0 & 8.3 & $14.6^{\mathrm{a}}$ \\
\hline High & 3.9 & 17.1 & 9.7 & 17.3 & 10.7 & 11.4 & $18.0^{\mathrm{a}}$ \\
\hline \multicolumn{8}{|c|}{ Women } \\
\hline \multicolumn{8}{|c|}{ Biological dust } \\
\hline None & 3.5 & 15.8 & 10.8 & 16.6 & 14.3 & $10.3^{a}$ & 15.9 \\
\hline Low & 5.2 & 16.9 & 9.3 & 20.5 & 16.3 & $16.0^{\mathrm{a}}$ & 17.7 \\
\hline High & . & 22.2 & 17.2 & 22.2 & 20.0 & $6.5^{\mathrm{a}}$ & 8.0 \\
\hline \multicolumn{8}{|c|}{ Mineral dust } \\
\hline None & 3.4 & $16.8^{\mathrm{a}}$ & 10.4 & 18.5 & 14.1 & 11.1 & 16.3 \\
\hline Low & 6.4 & $11.2^{\mathrm{a}}$ & 9.7 & 14.7 & 19.3 & 17.8 & 16.2 \\
\hline High & 5.9 & $30.0^{\mathrm{a}}$ & 14.7 & 23.3 & 20.6 & 12.5 & 15.4 \\
\hline \multicolumn{8}{|c|}{ Gas or fumes } \\
\hline None & $2.8^{\mathrm{a}}$ & $13.2^{\mathrm{a}}$ & 9.9 & 17.0 & 14.1 & $9.3^{\mathrm{a}}$ & 14.5 \\
\hline Low & $4.6^{a}$ & $18.6^{a}$ & 10.3 & 18.8 & 15.9 & $14.6^{\mathrm{a}}$ & 17.5 \\
\hline High & $10.4^{\mathrm{a}}$ & $27.8^{\mathrm{a}}$ & 17.8 & 22.9 & 18.8 & $16.7^{\mathrm{a}}$ & 24.2 \\
\hline \multicolumn{8}{|c|}{ Any of the above } \\
\hline None & 2.9 & 14.0 & $10.7^{\mathrm{a}}$ & 16.7 & 14.2 & 10.1 & 14.9 \\
\hline Low & 4.5 & 17.1 & $9.2^{\mathrm{a}}$ & 18.7 & 15.5 & 13.4 & 17.4 \\
\hline High & 6.2 & 25.4 & $18.7^{\mathrm{a}}$ & 22.6 & 18.2 & 15.1 & 17.0 \\
\hline
\end{tabular}

${ }^{a} \mathrm{P}<0.05$ by chi square test. only statistically significant for attacks of dyspnea in women with low exposure. For women, high and low exposure to gas or fumes was associated with a higher risk of asthma and all symptoms, but only statistically significant for phlegm cough and attacks of dyspnea for those with low exposure. For men with high exposure to biological dust, there was a statistically significant higher risk of morning and chronic cough. A significantly higher risk of dyspnea grade 2 was found among men with high exposure to gas or fumes (table 5).

Overall, for 19 out of 28 possible associations tested, women had a uniformly higher odds ratios (OR) for developing asthma or a symptom (where both degrees of exposure give an OR $>1$ ). For men, only 6 out of the 28 associations tested showed a trend against higher OR.

This gender difference, with stronger associations for women than men, was reflected in the interaction analyses, as there were significant interactions between gender and mineral dust exposure for both asthma $(\mathrm{P}=0.01)$ and phlegm cough $(\mathrm{P}=0.04)$. Significant interactions were also found between gender and gas or fumes exposure ( $\mathrm{P}=0.01$ for asthma, $\mathrm{P}=0.08$ for phlegm), and gender and any exposure $(\mathrm{P}=0.04$ for asthma, $\mathrm{P}=0.04$ for phlegm $)$, again with stronger associations for women.

\section{Discussion}

Significantly more women than men were exposed to biological dust (38\% versus $29 \%$ ), while significantly more men than women were exposed to mineral dust ( $48 \%$ versus $19 \%$ ), and gas or fumes ( $58 \%$ versus $53 \%$ ). Although few associations between the exposures and outcomes were statistically significant, there was a clear trend of a higher risk of incident asthma and most symptoms among the exposed. The associations tended to be stronger in women than in men, and there was a significant interaction between exposures and gender for the incidence of adult asthma and phlegm cough.

The strengths of our study were its high response rate, random selection of study subjects from a general population with a wide age span, and the adjustment for important confounders.

Nevertheless, there were some methodological considerations. Firstly, subjects with occupational exposure could have over-reported respiratory symptoms and asthma. However, the participants completed the questions on respiratory symptoms prior to those concerning job history, reducing the likelihood of this bias. Since occupational exposure is based on occupation using a JEM, the chance of subjects with symptoms or asthma over-reporting exposure is small, but there is always a risk of job misclassification (eg, incorrect reporting and job coding). 
Table 5. The adjusted odds ratios $(\mathrm{OR})$ for the adult incidence of asthma and respiratory symptoms by occupational exposure stratified by gender in subjects $\leq 65$ years at baseline. ( $95 \% \mathrm{Cl}=95 \%$ confidence interval)

\begin{tabular}{|c|c|c|c|c|c|c|}
\hline Asthma & Phlegm & Chronic cough & Morning cough & Dyspnea grade 2 & Attacks of dyspnea & Wheezing \\
\hline $\begin{array}{l}\text { Adjusted } 95 \% \mathrm{Cl} \\
\mathrm{OR}^{\mathrm{a}}\end{array}$ & $\begin{array}{c}\text { Adjusted } \\
\mathrm{OR}^{\mathrm{a}}\end{array}$ & $\begin{array}{l}\text { Adjusted } 95 \% \mathrm{Cl} \\
\mathrm{OR}^{\mathrm{a}}\end{array}$ & $\begin{array}{c}\text { Adjusted } 95 \% \mathrm{Cl} \\
\mathrm{OR}^{\mathrm{a}}\end{array}$ & $\begin{array}{c}\text { Adjusted } 95 \% \mathrm{Cl} \\
\mathrm{OR}^{\mathrm{a}}\end{array}$ & $\begin{array}{c}\text { Adjusted } \\
\mathrm{OR}^{\mathrm{a}}\end{array}$ & $\begin{array}{l}\text { Adjusted } 95 \% \mathrm{Cl} \\
\mathrm{OR}^{\mathrm{a}}\end{array}$ \\
\hline
\end{tabular}

\section{Men}

Biological dust

None

Low

High

Mineral dust

None

Low

High

Gas or fumes

None

Low

High

Any of the above

None

Low

High

Women

Biological dust

\section{None}

Low

High

Mineral dust

None

Low

High

Gas or fumes

None

Low

High

Any of the above

None

Low

High $\begin{array}{rr}1 & \text {. } \\ 1.39 & 0.6-3.2\end{array}$

$2.49 \quad 0.9-7.3$

$\begin{array}{rr}1 & \dot{1} \\ 0.53 & 0.2-1.3\end{array}$

$0.57 \quad 0.2-1.6$

1

$0.85 \quad 0.4-2.0$

$0.83 \quad 0.3-2.1$

$\begin{array}{rr}1 & \text {. } \\ 0.70 & 0.3-1.7 \\ 0.78 & 0.3-1.9\end{array}$

$$
1
$$

$1.30 \quad 0.8-2.1$

$0.71 \quad 0.4-1.2$

0.92

$0.5-1.8$

$0.99 \quad 0.5-1.9$ $\begin{array}{rr}1 & \cdot \\ 0.87 & 0.6-1.3 \\ 1.57 & 0.6-4.2\end{array}$

1

$0.83 \quad 0.5-1.3$

$1.710 .6-4.8$$$
1
$$

$0.53 \quad 0.3-0.9$

$1.68 \quad 0.7-4.1$

$\begin{array}{rr}1 & \text {. } \\ 0.82 & 0.5-1.5 \\ 1.18 & 0.4-3.6\end{array}$

1

$1.421 .0-2.1$

$2.03 \quad 0.9-4.8$ $\begin{array}{rr}1 & \cdot \\ 1.50 & 0.9-2.4 \\ 2.12 & 1.1-4.2\end{array}$

$\begin{array}{rr}1 & . \\ 0.80 & 0.4-1.5\end{array}$

$0.99 \quad 0.4-2.5$

$\begin{array}{rr}1 & \text {. } \\ 0.84 & 0.5-1.4 \\ 0.70 & 0.4-1.3\end{array}$

166

$1.66 \quad 0.9-2.9$

$1.23 \quad 0.6-2.5$

$\begin{array}{rr}1 & \text {. } \\ 0.88 & 0.5-1.5 \\ 0.99 & 0.6-1.7\end{array}$

$\begin{array}{rr}1 & . \\ 0.76 & 0.4-1.5 \\ 2.20 & 1.2-4.1\end{array}$

$\begin{array}{rr}1 & . \\ 1.13 & 0.7-1.9\end{array}$

$\begin{array}{rr}1 & \text {. } \\ 0.92 & 0.5-1.9\end{array}$

$1.770 .94-3.3$ $\begin{array}{rr}1 & \cdot \\ 0.94 & 0.5-1.6 \\ 1.44 & 0.7-3.0\end{array}$

$\begin{array}{rr}1 & \text {. } \\ 1.31 & 0.8-2.1\end{array}$

$0.82 \quad 0.4-1.9$

1.21

$1.21 \quad 0.7-2.1 \quad 1.03 \quad 0.6-1.7$

$\begin{array}{llll}1.11 & 0.6-2.1 & 1.08 & 0.6-1.9\end{array}$

$$
\begin{array}{rrrr}
1 & \cdot & 1 & . \\
0.78 & 0.4-1.4 & 1.17 & 0.7-2.0 \\
1.47 & 0.8-2.6 & 1.30 & 0.7-2.3 \\
& & & \\
1 & . & 1 & \dot{ } \\
0.87 & 0.5-1.6 & 1.08 & 0.6-1.9 \\
1.10 & 0.6-2.0 & 1.21 & 0.7-2.1
\end{array}
$$

a Adjusted for age, educational level, smoking, and previous occupational exposure.

Secondly, when inviting the same subjects several times to investigations, selection bias can occur. One possibility is the selection of healthy subjects, because those who are sick may die or lack the energy to attend. On the other hand, there could potentially also be a selection of subjects with respiratory symptoms or asthma, since they may feel there is some advantage in attending. However, responders and non-responders to the Hordaland County Cohort Study follow-up (1996/97) have been found not to differ significantly in important characteristics such as gender, age, educational level, and symptom score at baseline (12). Also, we believe the high response-rate in our study counteracted this potential selection bias.

Thirdly, we could not control for selection bias caused by (i) symptomatic subjects quitting a job with a high exposure or (ii) subjects with better health being selected into the workforce. This could have resulted in a "healthy worker effect" and tended to underestimate an exposure-disease relationship (17). Such a selection could have happened at two different points in the current study: (i) selection at baseline before the study started (ie, subjects with symptoms may avoid occupational exposure) and (ii) selection during follow-up (ie, symptomatic subjects at baseline may reduce their exposure during the follow-up time).

To examine a potential healthy worker effect in this study, we analyzed whether subjects exposed during the first six years of follow-up had more symptoms and asthma than subjects exposed during the last six years; we found they did not. In addition, exclusion of neither asthmatic subjects at baseline in the statistical analyses nor subjects without baseline occupational exposure affected the results (data not shown). 
Fourthly, we did not have information on the exact occurrence of asthma or symptoms during the follow-up period. However, the analyses of different time windows that compared subjects occupationally exposed during the first six years to those exposed in the last six years of follow-up, did not show any significant differences in the incidence of asthma and respiratory symptoms.

The ECRHS followed 8540 subjects for eight years (2). Using the same JEM as the one utilized in our study, the European survey found that exposure to mineral dust and gas or fumes was related to an increased incidence of chronic phlegm in men. No relationship was observed for biological dust or women overall. However, the ECRHS was restricted to the age group 20-44 years at baseline and studied only chronic phlegm (2). Our study covered subjects aged $\leq 65$ years at baseline and symptoms indicative of both asthma and chronic bronchitis. Overall, we observed the same pattern as the ECRHS: only some of the independent exposure-disease relationships reached statistical significance.

One difference between the two studies is worth noting. In the European survey, the significant relationships were observed in men, while in our study most of the significant associations were observed in women. Using the same JEM, the prevalence of airborne exposure among women in our study was three times higher than that of the ECRHS study. This could indicate that there is a real difference in both the type and level of airborne exposure between the women in the two studies. However, careful interpretation of this difference is needed as the ECRHS survey is a multi-center study, while ours is a single-center one.

We have previously shown in a cross-sectional analysis of our cohort how the relationships between self-reported occupational exposure and respiratory symptoms were stronger for women than men. It could be that the validity of the self-reported exposure to various agents is higher for women than men (18). However, the JEM-based exposure characterization is less subject to recall bias than the self-reported exposure characterization $(6,19,20)$. Thus, a tendency for a stronger relationship between airborne occupational exposures and asthma, and symptoms in women could be due to women being more vulnerable to airborne pollutants than men $(21,22)$. The results also indicate that women seem to develop respiratory symptoms at a lower exposure-level compared to men, and this may also be explained by a higher vulnerability among women.

For the age group $>45$ years, little information is available in the literature on occupational exposure and the incidence of respiratory disease. Older subjects are more likely to have been exposed at work than younger subjects since the hazards of exposure were less known in the past, and the use of protective gear at work was not always common. However, there were no significant interactions between age and exposures, and we did not find the exposure-disease associations to be stronger in older compared to younger age groups in separate analyses. This could partly be explained by a higher degree of misclassification of the job history of older subjects.

A Dutch longitudinal community study of elderly men observed a higher incidence of chronic, non-specific lung disease in those who were occupationally exposed (23). The exposure assessment was based on a JEM. However, only a minority of the participants never smoked, limiting the generalizability of the study.

The exposure-disease relationships observed in this report were weaker than those noted in a previous paper from the same cohort, when the exposure information was based on self-reported data (1). Eagan et al found that self-reported dust or fumes exposure at work was associated with the incidence of respiratory symptoms and asthma (OR varying from 1.4 for wheeze and attacks of dyspnea to 2.1 for dyspnea grade 3 ). Several studies have compared self-reported and JEM-based exposure characterization, and found them to be equal (24) or the JEM more precise $(19,20)$. However, it has been argued that the JEM should be adjusted to the geographical area, the time period, and the disease under study $(6,7)$. The weaker association found when using a JEM compared with a self-reported exposure characterization in this population could be due to the applied JEM not being specific to the study population even though it was designed for airway disease.

Another possibility is that the exposure changed during the timeframe of the Hordaland Cohort Study. In our previous paper using self-reported exposures, exposures before 1985 were the main interest (1). In this paper, exposures between 1985-1996/97 were examined. A weaker association with exposures between 1985-1996/97 could imply a reduction in the negative effects from occupational exposures, perhaps reflecting recent attempts to reduce exposures. Since direct comparison is impossible, we urge caution in interpreting the results. However, we think there is a need for further studies comparing self-reported and JEM-based characterization of occupational exposures in the same cohorts and within the same timeframe.

In conclusion, occupational airborne exposure assessed by a JEM was weakly related to the incidence of asthma and respiratory symptoms, significantly more so for women than men. There is a need for other studies on incident asthma and respiratory symptoms to examine whether there is a real biological difference in the susceptibility to workplace exposures between women and men. 


\section{References}

1. Eagan TM, Gulsvik A, Eide GE, Bakke PS. Occupational airborne exposure and the incidence of respiratory symptoms and asthma. Am J Respir Crit Care Med. 2002;166(7):933-8.

2. Sunyer J, Zock JP, Kromhout H, Garcia-Esteban R, Radon K, Jarvis $\mathrm{D}$, et al. Lung function decline, chronic bronchitis, and occupational exposures in young adults. Am J Respir Crit Care Med. 2005;172(9):1139-45.

3. Bakke P, Eide GE, Hanoa R, Gulsvik A. Occupational dust or gas exposure and prevalences of respiratory symptoms and asthma in a general population. Eur Respir J. 1991;4(3):273-8.

4. Matheson MC, Benke G, Raven J, Sim MR, Kromhout H, Vermeulen R, et al. Biological dust exposure in the workplace is a risk factor for chronic obstructive pulmonary disease. Thorax. 2005;60(8):645-51.

5. Blanc PD, Toren K. How much adult asthma can be attributed to occupational factors? Am J Med. 1999;107(6):580-7.

6. Kromhout H, Heederik D, Dalderup LM, Kromhout D. Performance of two general job-exposure matrices in a study of lung cancer morbidity in the Zutphen cohort. Am J Epidemiol. 1992;136(6):698-711.

7. Le Moual N, Bakke P, Orlowski E, Heederik D, Kromhout H, Kennedy SM, et al. Performance of population specific job exposure matrices (JEMs): European collaborative analyses on occupational risk factors for chronic obstructive pulmonary disease with job exposure matrices (ECOJEM). Occup Environ Med. 2000;57(2):126-32.

8. Kogevinas M, Anto JM, Sunyer J, Tobias A, Kromhout H, Burney P. Occupational asthma in Europe and other industrialised areas: a population-based study. Lancet. 1999;353(9166):1750-4.

9. Kogevinas M, Zock JP, Jarvis D, Kromhout H, Lillienberg L, Plana E, et al. Exposure to substances in the workplace and new-onset asthma: an international prospective populationbased study (ECRHS-II). Lancet. 2007;370(9584):336-41.

10. Kennedy SM, Le Moual N, Choudat D, Kauffmann F. Development of an asthma specific job exposure matrix and its application in the epidemiological study of genetics and environment in asthma (EGEA). Occup Environ Med. 2000;57(9):635-41.

11. Bakke P, Gulsvik A, Lilleng P, Overa O, Hanoa R, Eide GE. Postal survey on airborne occupational exposure and respiratory disorders in Norway: causes and consequences of non-response. J Epidemiol Community Health. 1990;44(4):316-20.

12. Eagan TM, Eide GE, Gulsvik A, Bakke PS. Nonresponse in a community cohort study: predictors and consequences for exposure-disease associations. J Clin Epidemiol. 2002;55(8):775-81.

13. Skorge TD, Eagan TM, Eide GE, Gulsvik A, Bakke PS Indoor exposures and respiratory symptoms in a Norwegian community sample. Thorax. 2005;60(11):937-42.

14. Skorge TD, Eagan TM, Eide GE, Gulsvik A, Bakke PS. The adult incidence of asthma and respiratory symptoms by passive smoking in uterus or in childhood. Am J Respir Crit Care Med. 2005;172(1):61-6.

15. Bakke PS, Baste V, Hanoa R, Gulsvik A. Prevalence of obstructive lung disease in a general population: relation to occupational title and exposure to some airborne agents. Thorax. 1991;46(12):863-70.

16. Rothman K, Greenland S. Modern epidemiology. 2nd ed. Philadelphia (PA): Lippincott-Raven; 1998.

17. Baillargeon J. Characteristics of the healthy worker effect. Occup Med. 2001;16(2):359-66.

18. Bakke PS, Hanoa R, Gulsvik A. Relation of occupational exposure to respiratory symptoms and asthma in a general population sample: self-reported versus interview-based exposure data. Am J Epidemiol. 2001;154(5):477-83.

19. Zock JP, Sunyer J, Kogevinas M, Kromhout H, Burney P, Anto JM. Occupation, chronic bronchitis, and lung function in young adults: an international study. Am J Respir Crit Care Med. 2001;163(7):1572-7.

20. de Vocht F, Zock JP, Kromhout H, Sunyer J, Anto JM, Burney $\mathrm{P}$, et al. Comparison of self-reported occupational exposure with a job exposure matrix in an international communitybased study on asthma. Am J Ind Med. 2005;47(5):434-42.

21. Langhammer A, Johnsen R, Gulsvik A, Holmen TL, Bjermer L. Sex differences in lung vulnerability to tobacco smoking. Eur Respir J. 2003;21(6):1017-23.

22. Becklake MR, Kauffmann F. Gender differences in airway behaviour over the human life span. Thorax. 1999;54(12):1119-38.

23. Post WK, Heederik D, Kromhout H, Kromhout D. Occupational exposures estimated by a population specific job exposure matrix and 25 year incidence rate of chronic nonspecific lung disease (CNSLD): the Zutphen Study. Eur Respir J. 1994;7(6):1048-55.

24. Blanc PD, Eisner MD, Balmes JR, Trupin L, Yelin EH, Katz PP. Exposure to vapors, gas, dust, or fumes: assessment by a single survey item compared to a detailed exposure battery and a job exposure matrix. Am J Ind Med. 2005;48(2):110-7.

Received for publication: 11 February 2009 